\title{
Study on the Application of Web2.0 in Advertising Communication
}

\author{
Meigui Ma \\ College of Humanities, Honghe University, Mengzi, Yunnan Province, P.R. China
}

\begin{abstract}
The arrival of web2.0 era, prompted the new mode of network operations and new media to be born. For example, the new mode of network operations are marketing2.0, work2.0, search engine and so on. The new media is blogs, mobile phone, online video, and digital and mobile television and so on. Which become the new medium of advertising carriers. The application value of web2.0 technology in advertising has been increasing concern by advertisers and businesses.
\end{abstract}

KEYWORD: Web2.0; Blog; Online video; Mobile phone; Digital and mobile TV; Search engine

In 2005, China Internet into web2.0, with blog popularity and various. Marked by the emergence of web2.0 website. In 2006, web2.0 communication patterns more vigorous development, the Internet continues to grow, but the difference is that people's concern will gradually shift from the concept of web2.0 to covering technology and business, operational level. By 2007, web2.0 development gradually the rationality, more concern and dispassionate about its true value[1]. From the perspective of web2.0 technologies of communication in advertising communication in the application is of great significance.

\section{INTERPRETATION OF WEB2.0}

In March 2004, concept of web2.0 is Proposed by United States famous Dale Dougherty of O'Reilly company discussions with Media Lives' Craig Cline in a brainstorming meeting for Internet trends. In October 2004, the two companies jointly held the world's first meeting of web2.0 theme. Subsequently, web2.0 hands down by Blog[2]. O'Reilly media, Chairman CEO, Tim O'Reilly web2.0, the most important principle is: the more users, the better service. But in the fact, the current IT industry-there is no consensus on the definition of web2.0.

About web2.0 concepts are varied but web2.0 is about the same, that is: the first, the Internet as a platform; Secondly, tap into the collective wisdom of information is no longer a specialist, or the Government and other authorities[3]. Anyone, as long as he had thought, dissemination of information over the Internet, you can have one on the Internet has one's own territory; Thirdly, data is the next Inter Inside; Fourthly, the end of software release cycles; Fifthly, the lightweight programming models: Sixthly, software beyond a single device; Seventhly, a rich user experience[4].

From the perspective of communication and technical sense, I agree with the web2.0 is a generalization of a series of innovative web applications, which is based on the web1.0 service, Internet users transition from receiver to become information producers and disseminators, shifting from passive relationship to equality, from the individual to society's new Internet service mode. Web2.0 is based on IM, BLOG, TAG, SNS, RSS, WIKI, P2P and other applications as a core, which based on the six degrees of separation, XML, AJAX, IPV6, grid computing, Semantic Web, new theories and technologies of the Internet, such as nextgeneration models.

\section{APPLICATION OF WEB 2.0 TECHNOLOGIES IN ADVERTISING COMMUNICATION}

In 2006, regarded as China's Internet web2.0 really kicked in, all kinds of new web2.0 application pattern is slowly changing the lives of Internet users in China[5]. Such as the popular Blog, podcast; BT download pop; RSS reading applications; The rise of video sites: the popularity of online TV streaming; TAG label use; "Face book ", the SNS website in China continues to grow, and so on.Web2.0 era of led many new networking operating model and the 
emergence of new media, advertisers advertising in new media carrier.

\subsection{Blog advertising}

Blogs were considered the most major forms of web2.0.It is a device used to express personal ideas, content, arranged in chronological order, and constantly updated online publishing and communication forms. B $\log$ is a new way of web information issuance, it is simple and easy to use, and spread rapidly, many blogger produced a large amount of information, they are spontaneous internet information producers.

Blog advertising is personal blog site as a carrier, spreading forms of online advertising through the Internet. There are three main forms: one is a general online advertising, ads on blog sites; Second, enterprises raise professional writers, in a blog post published on blog website. Articles emphasize the knowledge, professionalism, mainly for high-quality consumer groups. This way is suitable for high tech industries, such as IT industry, the automotive industry, such as; Three is to establish business or trade thematic blog site, the blog sites are responsible for the layout of the design notes, links, and other features of the setting, companies are only responsible for content delivery. This mode for a day, or fashion industry closely related to people's daily lives.

\subsection{Online video advertising}

In 2005, true online video advertising is still relatively uncommon in the country. Beginning in 2006, surging video sites, advertisers and advertising agencies are also active in promoting the sector.

Network video advertising has two a performance form: in page Shang put of video advertising and in network video flow media Shang put of video advertising, are has Internet and TV and some features: coverage wide, and form novel, and promotion efficient and content rich, these features gives network video advertising three a advantages: first, network video advertising of innovation sex and interactive sex improve has advertising hits. Secondly, the participatory and measurability of online video advertising boosted brand-building. Third, standardize online video advertising service and eliminate the bias against Internet advertising.

\subsection{Mobile advertising}

As the penetration rate of mobile phones have gotten higher, the combination of mobile phones and the Internet have made it an important mass media. People can call via cell phone, you can also read news, send and receive E-mail, Internet access, games and entertainment, ordering goods and services, and so on. Mobile phone is not only a representative of the modern communications industry, and is an extension of Internet media and constituent elements, as a new one by one media mobile media.

Phone as the last key press. Its operations are: MMS, SMS advertising, product brands, such as ringtones, games, advertising and mobile video advertising. These mobile advertising business to demonstrate individual and personal, timely, reliable, bi-directional, and scalability features. Advantages of mobile media advertising was also evident: first, large user groups can point to point communication to everyone: Secondly, publication of advertising information, receiving, browsing is not limited by time and space; Once again, accurate positioning, target. Finally, with the $3 \mathrm{G}$ step by step approaching, mobile television and other multimedia will be reflected on the screen, properties of the mobile phone as media will be strong, leaving advertisers space will be larger.

\subsection{Search engine advertising}

Search engines help users on the Internet through technical means at full speed in a huge information resource library to find the content you need. Because the search engine has the advantage of convenient, quick and concise, making users more convenient access to information, become the new darling of the broad masses of netizens. Many companies targeting opportunities, advertising in search engines on the web to increase ad clickthrough rates and ad effectiveness, it is also a kind of network advertising marketing[6].

Search engines has spawned new business profit models, have become a new economic growth point, a new advertising model. There are three main forms: the first is based on the hits of paid search engine advertising; Secondly, banner ads: third Portal promotion landing. Search engine advertising Internet advertising as an important form of development, based on broad and effective to win the majority of the audience advertisers favor.

\subsection{Digital and mobile TV advertising}

Now the social market economy, commercial flying. You take a bus, a mobile TV advertising; You fiddling with cell phones, mobile TV advertising; You're waiting for the elevator, there are building LCD advertising; You go to work, Internet advertising now focus media is making your life in each circle is surrounded by advertising. Despite its monopoly of the market for audience management system into a strategic ambiguity, confusion, malaise, but focus media Chairman and CEO JIANG Nanchun still insisted that "China's largest digital 
media group" the most ambitious goals to become the focus.

Mobile TV is by definition you can watch mobile TV, outdoor mobile digital TV is a brand new concept of information media, is an extension of traditional TV media[7]. At present, the life source of advertising or bus mobile TV. Bus mobile TV advertising has its own characteristics, mobility and brought the other characteristics, as evidenced in the following aspects: (1) audience coverage, high frequency of contact. (2) the ring closed channels only, mandatory, audiovisual, the target audience clear. (3) advertising costs are lower. Compared to traditional TV, and bus mobile TV advertising the cost of much cheaper.

\section{APPLICATION VALUE, PROBLEMS AND PROSPECT OF WEB2.0 IN ADVERTISING COMMUNICATION}

\subsection{Value}

Prominent media scholar Marshall McLuhan suggested "the medium is the message" point of view.Web2.0 network platform based on the nature of new media for major companies to provide new opportunities for dissemination. These new media advertising has injected new blood and bring new value to the advertising, brings new vitality to the development of the advertising industry[8]. Such value is summarized in the following aspects: first, mass communication, targeting is very strong, precise ad positioning, personality information profile, potential audience targeted dissemination. Second, web2.0 advertisement showing a new trend of modern commerce, leads to commercial communication concept of humanism. Such dissemination will attract audience attention, stimulate the desire to buy, purchase behavior, greatly improve the effectiveness of ads. Third, interactive, experiential, placement marketing tools to make ads more accurately. To better meet the audience's needs, targeted audience to thinning out, corresponds to advertising products stand out. Finally, the Internet, traffic expanded user base increases, high frequency of contact, to increase the value of advertising.

Finally, advertising and publishing easy, low cost, reduced advertising investment. Last, combination of interpersonal communication and mass communication, advertising effectiveness and better and higher returns. These values are what prompted the web2.0 as important causes of fires such as tea development in China.

\subsection{Problems}

For advertisers, media placement opportunities are increasing, alternative space expanding. For consumers, all kinds of advertising bean color and intricate[9]. Although, in our web2.0 from incoming to develop very rapidly, but web2.0 application in advertising are also facing some problem to solve: first, because the traditional advertising media location has taken root in the minds of consumers, the involvement of new media in the short term, cannot be accepted by the audience and recognition; Second, the policies on the regulation of new media, there are many must constantly improve relevant laws and regulations and the establishment of a sound regulatory system and regulatory risk in policy, giving audiences the right guidance; Thirdly, does not prevent a malicious or invalid clicks, not detailed traffic statistics advertising; Finally, advertising content is not innovative enough, enough new, dull, single, even strikingly serious advertising effectiveness needs to be improved:

Finally, fees and business model needs to be improved, so lucrative for advertisers is the biggest problem facing the web2.0.Need in web2.0 business model based on looking for new, more profitable models will be able to meet the profit demands of advertisers.

\subsection{Prospect}

Although web2.0 in a short time and did not bring the desired effect and the value to the advertiser. But its long-term development and its future are incalculable. Any kind of new thing appears, people accept there is a process, we should give full play to the advantages of new media, combined with modern psychological and demand characteristics of the audience, and create a better economic and social environment, innovative profit model, improve the regulatory and policy, guide and accurately using web2.0 technology will add to our lives more beautiful picture.

\section{REFERENCES}

[1] Dan Gillmor. We the Media, ISBN: 0-596-0073-7, July2004.

[2] Justin Hind. Accountability in a 2.0 world. 05 (2007):12

[3] PENG Lan. Development and Social Significance of Web2.0 in China. 10(2007):44-48.

[4] SUN Qian. Studying the meaning, characterization and applications of web2.0. 02 (2006):69-70

[5] HE Xuan. Analysis of Advertising communications under web2.0 age. 04 (2007): 64-65.

[6] L.Carol Christopher. Web2.0 Comes to Newspapers. 10 (2007):4-8.

[7] Nathalie Kilby. HP junks TV in Europe foe global Web2.0 promo. 06 (2007):14.

[8] Edward Cone. Web2.0 Reality Check. 05 (2006):23.

[9] HUANG Wei. Analysis of Current situation and development of blog Ad in China. 02 (2007):230-231. 